\title{
Safety and efficacy of Transurethral Bipolar Enucleation of prostate (TUBE) in BPH
}

\author{
Reddy N. M${ }^{1}$, Reddy P.V ${ }^{2}$, Reddy C.S ${ }^{3}$., Reddy G. $V^{4}$, Ranadheer $R^{5}$, Bodduluri $S^{6}$, Maddiboina $H^{7}$. \\ ${ }^{1}$ Mallikarjuna Reddy Nalubolu, ${ }^{2}$ Vedamurthy Reddy Pogula, ${ }^{3}$ Sivasankar Reddy Challa, ${ }^{4}$ Vijayabhaskar reddy Gouru, \\ ${ }^{5}$ Ranadheer byram, ${ }^{6}$ Sudeep Bodduluri, ${ }^{7}$ Harikrishna Maddiboina. Dept of Urology \& Renal Transplantation, Narayana \\ Medical College \& Hospital, Nellore, Andhra Pradesh, India - 524003.
}

Corresponding Author: Dr. Vedamurthy Reddy Pogula, Associate Professor, Department of Urology \& Renal Transplantation, Narayana Medical College \& Hospital, Nellore, Andhra Pradesh, India- 524003. Mail: pglreddy@yahoo.co.in

\begin{abstract}
Objectives: To evaluate the safety and efficacy of transurethral bipolar enucleation of the prostate due to benign prostatic hyperplasia. Methods: This is a prospective study and 37 patients undergoing Transurethral bipolar enucleation of the prostate (TUBE) for BPH will be taken for the study. Preoperative factors evaluated included International Prostate Symptom Score (IPSS), postvoid residual volume (PVR), estimated blood loss, operative time, pathologic weight, and complications. Postoperative evaluation was performed at 1month, 6 months and 12months. Results: Preoperative, 1 month, 6 months, and 12 months mean postvoid residual volumes were $235 \mathrm{~mL}, 33.6 \mathrm{~mL}, 20 \mathrm{~mL}$ and $20 \mathrm{~mL}$; mean IPSS were 31.6, 2.97, 2.97 and 2.97; mean Q max was $5.8 \mathrm{ml} / \mathrm{sec}, 20.23 \mathrm{ml} / \mathrm{sec}, 25.5 \mathrm{ml} / \mathrm{sec}$, and $25.5 \mathrm{ml} / \mathrm{sec}$; preoperative and post operative mean quality of life scores were 5.4 and 2.2; mean operative time was 87.5 minutes. Hemoglobin drop was $0.6 \mathrm{~g} / \mathrm{dl}$, and pathologic weight was $45.45 \mathrm{~g} .10$ patients underwent partial enucleation. Early stress incontinence occurred in 9 patients $(24.3 \%)$. Urinary tract infection occurred in 1 patient, and Superficial mucosal bladder injury in 1 patient. Conclusions: International Prostate Symptom Score, quality of life, Qmax, and postvoid residual volume (PVR) showed statistically significant improvements from baseline. TUBE is a safe, effective, and reproducible procedure for $\mathrm{BPH}$.
\end{abstract}

Key words: BPH, Transurethral Bipolar Enucleation of prostate (TUBE), LUTS, TURP

\section{Introduction}

Benign prostatic hyperplasia $(\mathrm{BPH})$ is a histologic diagnosis that refers to the proliferation of smooth muscle and epithelial cells within the prostatic transition zone $[1,2]$. Voiding lower urinary tract symptoms (LUTS) have often been attributed to the physical presence of Bladder outlet obstruction (BOO). Detrusor over activity is thought to be a contributor to the storage LUTS [3]. The prevalence and the severity of LUTS in the aging male can be progressive and is an important diagnosis in the healthcare of our patients. Although LUTS secondary to BPH (LUTS/BPH) is not often a life-threatening condition, the impact of LUTS/BPH on quality of life (QoL) can be significant and should not be underestimated [4]. Traditionally, the primary goal of treatment has been to alleviate bothersome LUTS

Manuscript received: $18^{\text {th }}$ April 2018

Reviewed: $28^{\text {th }}$ April 2018

Author Corrected: $4^{\text {th }}$ May 2018

Accepted for Publication: $8^{\text {th }}$ May 2018 that result from prostatic enlargement.More recently, treatment has additionally been focused on the alteration of disease progression and prevention of complications that can be associated with BPH/LUTS [5]. A variety of pharmacologic classes are employed including alpha-adrenergic antagonists (alpha-blockers), 5-alphareductase inhibitors (5-ARIs), anticholinergics and phytotherapeutics. Choosing the correct medical treatment for BPH is truly complex and ever-changing. Surgical intervention is an appropriate treatment alternative for patients with moderate to severe LUTS and for patients who have developed AUR or other BPH-related complications. By definition, surgery is the most invasive option for BPH management and generally, patients will have failed medical therapy before proceeding with surgery.

Since 1990s Transurethral resection of the prostate (TURP) was the method of choice for the operative 


\section{Original Research Article}

treatment of LUTS in Prostate with an estimated weight of less than 100 grams. Since the introduction of TURP, it has been contributed as its own field of study and is still the most commonly performed urological operation [6]. With the introduction of medical therapies (5-alphareductase-inhibitors and alpha-1 blockers) and less invasive operations, there has been significantly decreased the number of TURPs. TURP with regard to their clinical effectiveness is considered as the "gold standard" of surgical therapy of BPH [7].

However it is associated with major problems, including high reoperation rate, blood loss, TUR syndrome. As prostate volume increases, the rate of these complications also increases. Therefore open prostatectomy often was recommended in patients with large $\mathrm{BPH}$, despite increased morbidity \& long recovery. In order to reduce these complications many minimally invasive treatment modalities like Laser enucleation, laser vaporisation and bipolar resection have been developed. In 1996 P. Gilling and M.
Fraundorfer has developed a method of holmium - laser resection of the prostate (HoLRP), which later with the introduction of Morcellator It was modified to Holmium LASER Enucleation of the Prostate (HoLEP) [8].

When bipolar energy is used for TURP, physiological normal saline can be used for irrigation during the procedure. Bipolar TURP has reduced the risk of complications like bleeding, dilutional hyponatremia \& TUR syndrome at the same time permitting longer resection times without compromising patients safety [9]. Recently the bipolar enucleation technique is described where a specially designed loop by Olympus is used to enucleate the adenoma and bipolar energy for resection and hemostasis. The technique combines the principles of laser enucleation and bipolar resection. The technique is called transurethral enucleation with bipolar plasmakinetinc energy (TUBE) [10]. In this study we plan to assess the safety of Transurethral bipolar enucleation of prostate (TUBE) in patients with $\mathrm{BPH}$.

\section{Methods}

This is a single centre, prospective observational study done at department of urology, Narayana Medical College hospital, Nellore. To evaluate the outcomes in BPH patients undergoing the Bipolar Transurethral enucleation technique (TUBE). A total of 37 Patients undergoing TUBE for BPH were taken for the study.

\section{Inclusion criteria}

1. Patients with BPH with prostate volume $>40 \mathrm{gm}$ with failed medical management and

2. Failed TWOC (Trial void without catheter) were enrolled into the study.

The subjective and objective improvement will be assessed based on IPSS and investigations including ultrasound and uroflowmetry.

- Intra operatively the blood loss, resection time, field of vision and amount of glandular tissue resected were noted.

- Post operatively drop in $\mathrm{Hb}(\mathrm{g} / \mathrm{dl})$, blood transfusion, catheterization period, hospital stay, post operative complications like re-catheterization, incontinence, early irritative symptoms, infection and long term complications like bladder neck stenosis, urethral strictures, urinary incontinence, Quality of life were assessed.

Exclusion criteria: Patients with severe associated comorbidities, previous prostate surgery or history of prostate cancer, urethral stricture, renal failure, neurogenic bladder, were excluded from the study.

The study was approved by the institutional ethical and research committee. The patients were enrolled after obtaining written informed consent (properly explaining the aims, methods, anticipated benefits and potential hazards relevant for the decision to participate in the trial).

Procedure: The TUBE procedure was performed using the Olympus Plasmakinetic Super Pulse System with Plasma Sect electrodes and operated with a cutting power of 260- $280 \mathrm{~W}$ and a coagulating power of $120-140 \mathrm{~W}$. We used a technique similar to HoLEP, which was previously designed by Hochreiter et al [11].

In essence, the enucleation was begun by making marks with a cutting loop at the distal edge of the prostate lobes and the proximal edge of the external sphincter muscle. A circular incision on the urethral mucosa was made along the marks and deep into the surgical capsule until clear transverse fibres were seen [Fig 1]. The tip of resectoscope sheath was then 


\section{Original Research Article}

inserted from the circular incision line at the 5 o'clock and 7 o'clock positions to make a cleavage plane between the detached lobe and the capsule [Fig 2]. The resectoscope sheath moved in the cleavage plane just as the surgeon's index finger does when performing open prostatectomy, and the detachment area was extended to the lateral and forward sides. Meanwhile, the median and the lateral prostatic lobes were dissected away in a retrograde fashion from the prostate apex towards the bladder using a spatula which is specially designed to lift the adenoma from the surgical capsule all around [Fig 3]. During these steps, haemostasis can be achieved with loop by coagulation if bleeding on the established plane occurs. Thus, the prostatic lobes were sub totally enucleated and devascularised but still connected to the bladder neck by a narrow pedicle. Finally, these devascularised lobes were fast-fragmented with the plasmakinetic cutting loop into pieces small enough to be evacuated through the resectoscope sheath (ie, the "mushroom" technique) [11]. During TUBE, $0.9 \%$ saline solution was used as irrigation fluid in all cases. The TURP procedure was performed with bipolar loop electrodes and standard tungsten cutting wire loop at a setting of 280-W cutting and 160-W coagulating current. The resection was started at the bladder neck at the 6 o'clock position, extending to the verumontanum, and carried down to the surgical capsule, with complete removal of the prostatic stroma [Fig 4].

Morcellation can be performed using a 26F laser resectoscope (27050SL; Storz) combined with a nephroscope. At the end of both procedures, a 22F three-way Foley catheter was inserted into the bladder with a closed drainage system. All retrieved tissue was collected and examined histo pathologically. All patients had serum electrolytes, and haemoglobin and haematocrit levels measured immediately after the procedure. Postoperative bladder irrigation with physiologic saline solution was applied as necessary until the efflux was sufficiently clear in all patients for minimum of 12 hours.

It is our institution's policy that the catheters be removed within $48 \mathrm{hrs}$ after irrigation was stopped, and the patients were then discharged from the hospital within $24 \mathrm{~h}$ after decatheterisation and passing clear urine. No patients were discharged after 6:00 PM. Within those $24 \mathrm{~h}$, we routinely observe the colour of the urine drained from the catheters to ensure completely clear urine after stopping the irrigation and to assess the frequency and volume of micturition after removing the catheter, respectively.



Fig-1: A circumferential mucosal incision is made just proximal to veru at the apex of the Prostate.
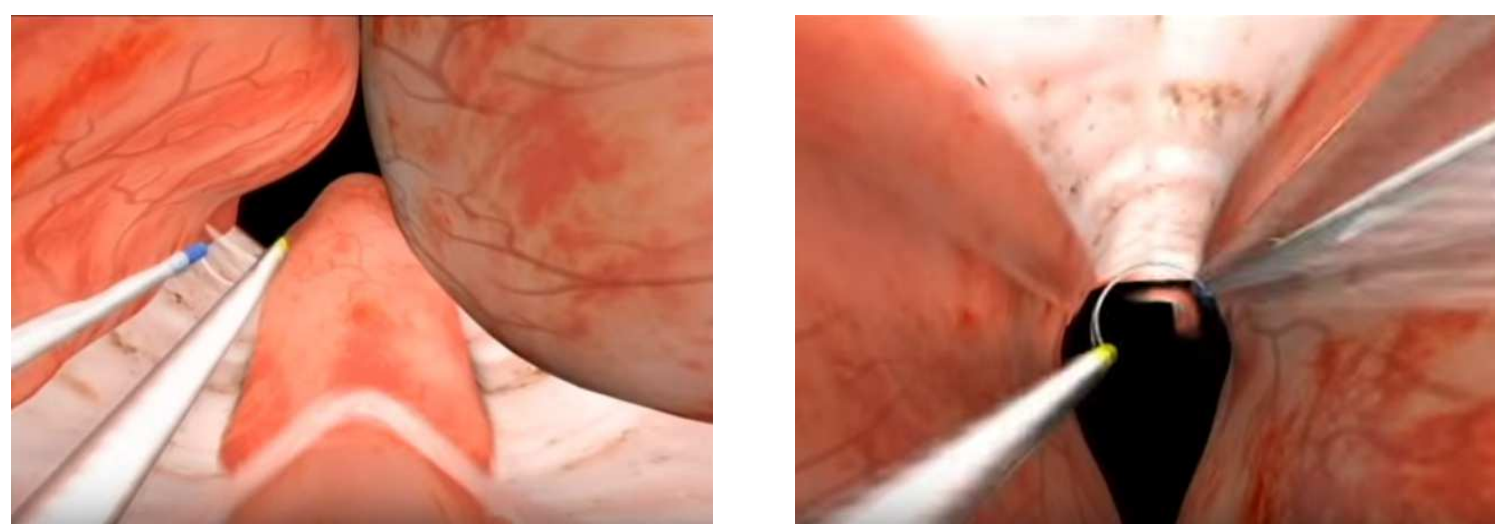

Fig-2: Gutters are created at 5, 7, and 120clock position. 


\section{Original Research Article}

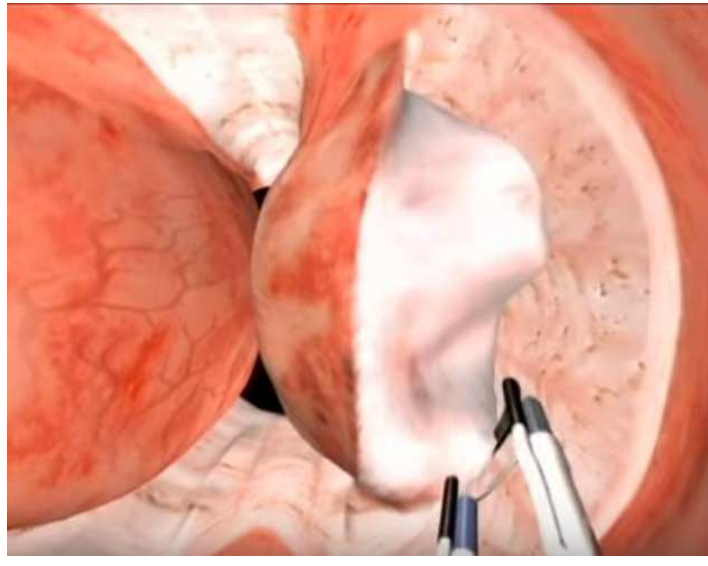

Fig-3: Enucleation of left \& right lobe

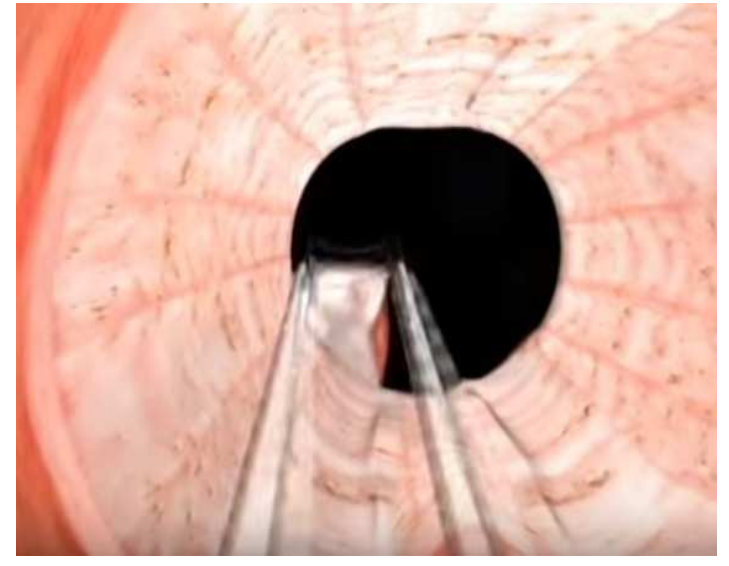

Fig-4: Complete Enucleation with Roomy prostatic cavity

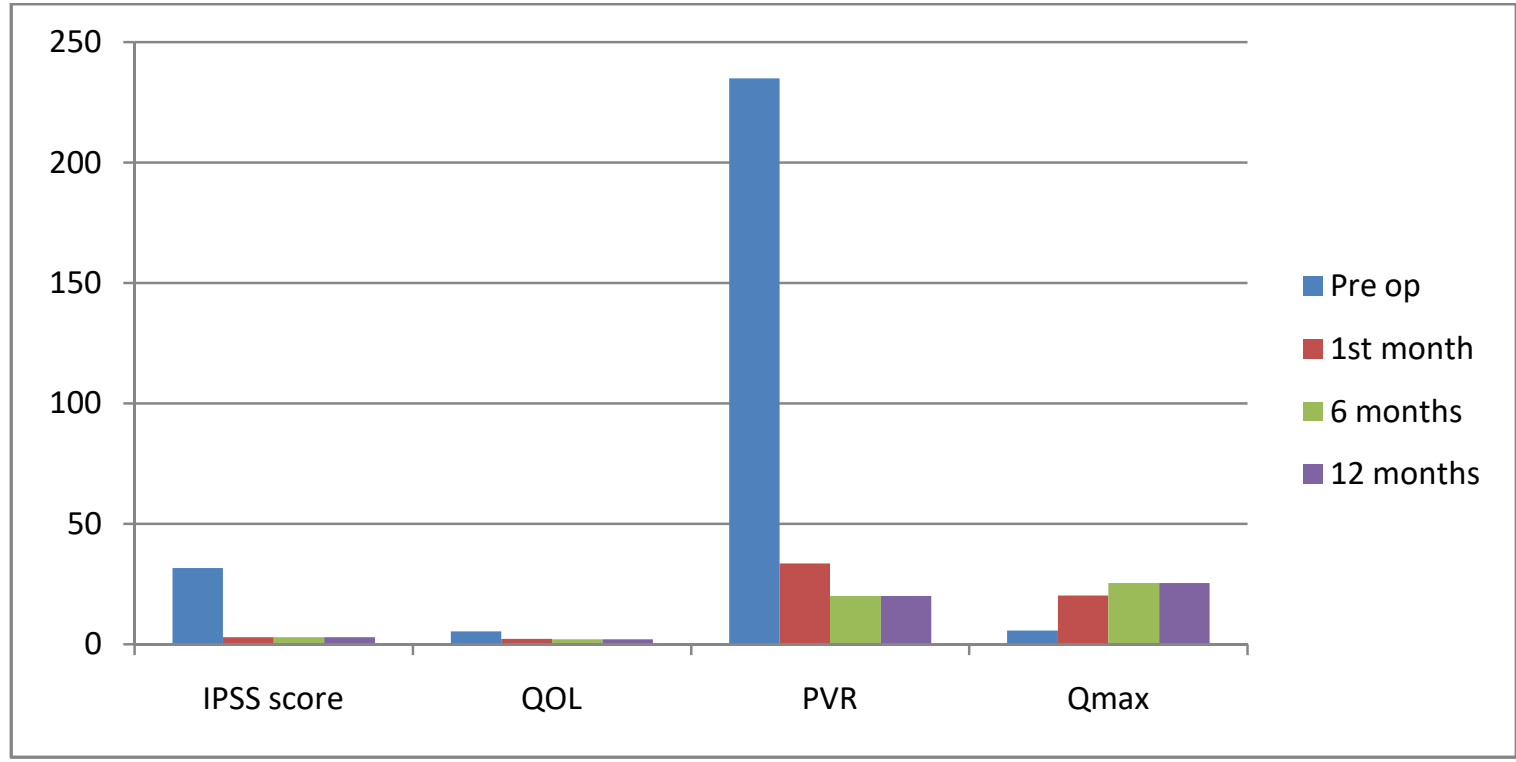

Fig-5: Comparing Preoperative data with Follow-up data at $1^{\text {st }}, 6^{\text {th }}$ months $\& 12$ months period

Statistical Analysis- Baseline and postoperative IPSS, QoL, Qmax, PSA, PV, and PVR volume were compared using unpaired Student's t tests. All statistical analyses were performed using the Statistical Package for the Social Sciences, version 13.0 for Windows. A two-sided P-value $<0.05$ was considered statistically significant.

\section{Results}

In the 37 patients treated with bipolar enucleation of the prostate, 10 patients underwent partial enucleation, partially converted to conventional bipolar TURP. The average patient age was 66.9 years old (range 55-78) at surgery and the estimated average prostate volume was $56.3 \mathrm{cc}$ (range 42-128). The volume of prostate removed was 45.44cc (range 3895) during the operations.

The time for procedure ranged from 45 to150 $\mathrm{min}$ (average $87.5 \mathrm{~min}$ ) including enucleation and resection time. The hemoglobin drop was $0.6 \mathrm{~g} / \mathrm{dl}$ with a max drop of $1.4 \mathrm{gm} / \mathrm{dl}$ to $\min$ drop of $0.2 \mathrm{gm} / \mathrm{dl}$. No patient was blood transfused postoperatively. 1 patient had dilutional hyponatremia with symptoms of confusion \& altered sensorium after the procedure \& was treated accordingly.

No major complication occurred and no patient was converted to open prostatectomy. The mean postoperative irrigation time of bipolar TUBE was $12.6 \mathrm{~h}$. The indwelling catheter was removed after a median of 3 days

[Table 1A \& Table 1B] 
Table-1A: Preoperativecomparison of variable parameters

\begin{tabular}{|c|c|c|c|c|c|c|}
\hline & Mean value & Median & Minimum & Maximum & Mode & $\begin{array}{c}\text { Standard } \\
\text { deviation }\end{array}$ \\
\hline Preop parameters & & & & & & \\
\hline Age (years) & 66.9 & 66.5 & 55 & 78 & 66 & 6.7 \\
\hline TRUS (cm3) & 56.3 & 50 & 42 & 128 & 50 & 24.3 \\
\hline HB (g/dl) & 11.0 & 10.8 & 7.6 & 14.6 & 10.4 & 1.78 \\
\hline Na (mmol/l) & 139.9 & 140.0 & 133.0 & 148.0 & 138.0 & 5.1 \\
\hline IPSS score & 31.6 & 34 & 17 & 35 & 35 & 4.8 \\
\hline QOL & 5.4 & 5 & 4 & 6 & 5 & 0.6 \\
\hline Uroflow. (ml/sec) & 5.8 & 6.5 & 4.1 & 7.8 & 5.3 & 1.2 \\
\hline Residual urine (ml) & 235.0 & 190.0 & 50.0 & 1000 & 210 & 220.6 \\
\hline Operating time (min) & 87.5 & 90 & 45 & 150 & 90 & 25.4 \\
\hline Resection weight (g) & 45.46 & 44.5 & 38 & 95 & 35.5 & 20.7 \\
\hline
\end{tabular}

Table 1B: Post-operativecomparison of variable parameters.

\begin{tabular}{|c|c|c|c|c|c|c|}
\hline & Mean value & Median & Minimum & Maximum & Mode & $\begin{array}{c}\text { Standard } \\
\text { deviation }\end{array}$ \\
\hline Postop parameters & & & & & & \\
\hline HB (g/dl) & 10.7 & 10.6 & 8.6 & 14.3 & 9.3 & 1.69 \\
\hline HB loss (g/dl) & 0.6 & 0.3 & 0.2 & 1.4 & 0.4 & 0.2 \\
\hline Na (mmol/l) & 138.7 & 140.0 & 133.0 & 145,0 & 136.0 & 5.6 \\
\hline Na loss (mmol/l) & 3.4 & 3.0 & 1.0 & 7.0 & 3.0 & 1.4 \\
\hline Catheter time postop. (days) & 3.71 & 3 & 3 & 6 & 3 & 1.00 \\
\hline Uroflow postop. (ml/sec) & 13.9 & 13.2 & 6.7 & 22.1 & 12.5 & 4.6 \\
\hline Residual urine postop. (ml) & 40.22 & 40 & 0 & 150 & 40 & 29.9 \\
\hline IPSS score 1 Mo. postop. & 2.97 & 3 & 0 & 6 & 4 & 1.3 \\
\hline Post op QOL & 2.2 & 2 & 2 & 3 & 2 & 0.4 \\
\hline Uroflow 1 Mo. postop. & 20.23 & 20 & 13 & 25.8 & 19 & 3.1 \\
\hline Residual urine 1 Mo. postop. & 33.6 & 40 & 0 & 150 & 0,40 & 30.5 \\
\hline IPSS score 6 mo. postop. & 2.97 & 3 & 0 & 6 & 4 & 1.3 \\
\hline Uroflow 6 mo. postop. & 25.5 & 22 & 16 & 24 & 19 & 3.2 \\
\hline Residual urine 6 mo. postop. & 20 & 20 & 0 & 40 & 0,20 & 15.6 \\
\hline IPSS score 12 mo. postop. & 2.97 & 3 & 0 & 6 & 4 & 1.3 \\
\hline Uroflow 12 mo. postop. & 25.5 & 22 & 16 & 24 & 19 & 3.2 \\
\hline Residual urine 12 mo. & 20 & 20 & 0 & 40 & 0,20 & 15.6 \\
postop. & & & & & & \\
\hline
\end{tabular}

Patients were free from symptoms, such as dysuria and urinary frequency within a median of 6 days. The decision to leave the catheter indwelling for $72 \mathrm{~h}$ postoperatively was based on our early clinical experience, because those in whom the catheters were removed after 5 days had no difference in duration of symptoms. Pathological evaluation of the retrieved samples revealed an incidental TB prostatitis in 1 case and BPH in 36 cases. The postoperative complications included early stress urinary incontinence in 9(24.3\%) patients. Persistent urine incontinence was noted in 1 patient. Superficial mucosal bladder injury during morcellation was noted in 1 patient managed conservatively and patient was on indwelling catheter for 5 days. Recurrent UTI in 2 patients were noted managed with urine culture based antibiotic usage. 
A study of 37 patients who underwent TUBE were followed up for 12 months and found that the procedure resulted in minimal morbidity, with immediate improvements in symptoms and voiding. In the current study, TUBE showed that this procedure has a low morbidity rate and is an alternative to TURP in the treatment of patients with symptomatic BPH. Our results provide evidence supporting the efficacy of TUBE. Improvements in subjective variables (IPSS and QOL) showed that the patients were satisfied with the results of this procedure. At 1 year, mean Qmax improved 13.9 to 25.5 $\mathrm{ml} / \mathrm{s}$; mean PVR urine decreased from $40.22 \mathrm{ml}$ to $0 \mathrm{ml}$ volume, mean IPSS at preop \& 1 month after follow up decreased from 31.6 to 2.97 and mean QOL scores after 12months improved from 5 to 2, when compared with preoperative data. The highly significant improvements from baseline in postoperative PVR and QOL index showed that the obstruction had been successfully relieved [Fig 5].

\section{Discussion}

The TURP has been considered the standard surgical therapy for LUTS caused by BPH. Despite improvements in equipment and techniques over the years, TURP is associated with significant morbidity and retreatment rates, particularly in patients with a large prostate [12].

Open prostatectomy (OP) is therefore still considered a valid option for patients with a prostate of $>80 \mathrm{~g}$ [13]. Surgical enucleation for the treatment of LUTS caused by $\mathrm{BPH}$ remains the most complete method to remove adenomas of any size; the history of surgical enucleation dates back more than 100 years [14]. In spite of the low re-operation rate and high success rate, $\mathrm{OP}$ is an invasive procedure associated with higher transfusion rates, longer catheterisation time, and longer hospital stay. As a result, the popularity of OP has declined.

The concept of surgical enucleation was revisited with the advent of endoscopic alternatives to open enucleation. Endoscopic enucleation allows for maximal removal of the adenoma and results in potentially equivalent efficacy compared with its open counterpart, with significantly lower morbidity. Holmium laser enucleation of the prostate (HoLEP) was the first endoscopic enucleative technique described [15]. This technique has been compared with OP and TURP in various randomized controlled trials, yielding at least comparable outcomes and a favourable safety profile [16]. The use of expensive high-energy holmium laser equipment and a steep learning curve, however, have limited the extensive application of HoLEP worldwide. There has also been a significant risk of bladder injury associated with the use of the mechanical tissue morcellator that is required for HoLEP.

The use of normal saline as an irrigant was made possible by the introduction of bipolar devices. As a result, the risk of TURP syndrome has been virtually eliminated, and bipolar TURP has been widely adopted for resection of larger prostates with longer operating times. The use of a bipolar device in endoscopic enucleation was first reported by Neill et al and bipolar TUERP requires no additional devices in comparison with bipolar TURP [17].

Moreover, the sheath of the resectoscope is used for mechanical nucleation of the adenoma along the plane of the surgical capsule, instead of the holmium laser used in HoLEP. The subtotally enucleated adenoma is then resected into chips by the loop electrode, and the use of a mechanical tissue morcellator is eliminated. The nomenclature for this procedure has not been standardized with terms such as TUBE, plasmakinetic enucleation of the prostate and bipolar plasma enucleation of the prostate are reported in the literature.

Several modifications in technique and equipment since the introduction of bipolar TUBE have been suggested. For example, a spatula-like enucleation loop, combined with a loop electrode for haemostasis, was introduced by Olympus and is especially designed for this procedure.Alternatively, the use of thick loop electrodes and button electrodes has been described in some series to facilitate the enucleation process. Based on personal experience with these different loops, the alternative loops with different designs are generally stronger than the conventional loop electrode, and they can be used for mechanical enucleation without breakage. The use of the loop in performing enucleation, instead of the resectoscope sheath, also provides better, more direct visualization during the enucleation process.

Excellent hemostatic properties resulted from the rapid removal of obstructive prostatic adenoma with the least bleeding, with several studies confirming the safety and efficacy of TUBE in the treatment of symptomatic BPH [18]. Clinical outcomes after TUBE were similar to those after TURP, but long-term data analysis of TUBE was lacking. Evaluation of different endo-enucleation techniques for prostatic adenomas has indicated that TUBE yields durable subjective and objective improvements [19]. 


\section{Original Research Article}

A retrospective review of 978 patients who underwent HoLEP for symptomatic BPH showed that, at 1year follow-up, Qmax increased to $23.4 \mathrm{ml} / \mathrm{s}$, PVR was 32.5 $\mathrm{ml}$, and IPSS was 4.5 [20]. Furthermore, $4 \%$ of patients required retreatment for $\mathrm{BPH}$, with retreatment rate positively associated with the procedure learning curve.

A comparison of plasmakinetic enucleation of the prostate (PKEP) and TURP for symptomatic BPH in 204 patients showed significantly greater improvements in outcomes after 3 years of follow-up in the PKEP than in the TURP group. Specifically, IPSS, Qmax showed significantly greater improvements in the PKEP than in the TURP group [21].TUBE has several advantages, including the ability to remove entire prostatic adenomas and to avoid leaving adenomatous tissue in the prostatic fossa. Complete enucleation of the prostatic (obstructing) tissue, resulting in a wide prostatic cavity, provided superior and more durable voiding function.

There were no major safety concerns with TUBE. Most of the adverse events were uncomplicated and of short duration such as urine incontinence [22].

Incontinence was the most frequent adverse event during follow-up. We found that 9 cases experienced stress incontinence, similar to previous findings in patients who underwent TUBE, with stress incontinence disappearing in most patients within 6 months. Enucleation of the adenoma with the surgical capsule can contribute to deobstruction and reduce urethral resistance drastically. Sphincter muscle exercises resulted in improvements in incontinence, indicating that the bladder and sphincter change in response to urinary deobstruction induced by TUBE.

The bipolar enucleation and resection of prostate is a minimally invasive approach, which renders complete adenoma removal and, as such, provides unique advantages over other surgical modalities for $\mathrm{BPH}$.

Recently, a number of reports have been published on the bipolar enucleation of enlarged prostates, which assessed the safety and durability of this procedure. Among these studies, the report of Liu et al is the biggest study to date that provides evidence on the longterm efficacy and safety of bipolar enucleation of prostates. Other studies presented compelling data that bipolar enucleation and resection of prostates can be used in prostates of any size and provide long-term reliable outcomes. Although any point source of energy that has sufficient hemostatic characteristics can be adopted for the enucleation of prostate adenoma by similar techniques, the techniques need to be improved to ensure its expanded use [23]. Learning by doing is a prerequisite to improve performance in surgical techniques. Thus, surgical experience and learning curve models are developed from the basic premise that the surgeon acquires skills by gaining experience through repetition, in which the individual surgeon develops a relatively permanent change in operative performance. According to the literature, HoLEP has been proven to require a steep and long learning curve compared with that of conventional TURP. The barriers during the learning curve focused on properly identifying and handling the right plane in the absence of mentorship. First, the main point of the current procedure focuses on identifying the surgical plane between the adenoma and prostate surgical capsules [24]. The anatomic landmarks that prompt the surgeon to identify the surgical plane mainly include capsule transverse fibers or fiber strands, capsule vessel reticula, capsule prostate calculi.

In our first 8 patients, the conversion to conventional bipolar TURP mainly results in failure to identify the right surgical capsule. A high resolution monitoring system helps the surgeon to recognize the hyperplasia adenoma,surgical capsule, and enucleation plane.

Second, the lobe was bluntly detached along the surgical plane by precision cutting and coagulating the capsule vessel to keep the surgical plane. Third, the crucial question in the growing awareness on patient safety is whether to choose enucleation or perform conventional TURP.

In our first 10 patients, more operation time was spent in identifying the anatomic landmarks and in the enucleation procedure. During the experience accumulation through the learning curve, the surgeon can convert bipolar enucleation of prostate to conventional bipolar TURP, without risking a negative outcome to the patients. The conversion from bipolar enucleation of prostate to the conventional bipolar TURP is easy to handle, because the hemostasis skills are similar in experienced urologists. In our series on the learning curve, an endourologist inexperienced in bipolar TUBE can perform the procedure with a reasonable 'lower' conversion ratio after about 6 cases and with an acceptable efficiency after about 20 cases. Furthermore, major technical difficulties are likely to occur when handling very large prostates more than 100 $\mathrm{ml}$, due to the difficulties related to orientation during enucleation. At 6 months' follow-up, the clinical 


\section{Original Research Article}

efficacy of bipolar TUBE is durable and comparable with those previously published. TUBE is a highly effective and well tolerated procedure to relieve bladder outlet obstruction, resulting from $\mathrm{BPH}$ [24]. In the experienced center, bipolar TUBE was the first choice for symptomatic BPH. In the current studies, a mean $57 \%$ of prostate tissue (range $32-79 \%$ ) was removed after the bipolar enucleation of prostate. The bipolar enucleation efficiency increased proportionally with the resected prostate volume [25]. In addition, no major complications were experienced in the current series, and all mild stress urinary continence cases have completely recovered. The complication results indicated a high safety with the bipolar TUERP compared to TURP, even for novice surgeons.

\section{Conclusion}

TUBE is a safe, effective, and reproducible procedure for symptomatic BPH. IPSS, QOL, Qmax, and PVR showed statistically significant improvements from baseline. TUBE had good short- and long-term safety profiles, with a low complication rate. TUBE may be an alternative treatment of choice for symptomatic BPH, which may replace as a poor man LASER.

Funding: Nil, Conflict of interest: None Permission of IRB: Yes

\section{References}

1. Lee C, Kozlowski JM, Grayhack JT. Intrinsic and extrinsic factors controlling benign prostatic growth.

Prostate. 1997 May 1; 31(2):131-8.

2. Auffenberg GB, Helfand BT, Mc Vary KT. Established medical therapy for benign prostatic hyperplasia. doi: 10.1016/j.ucl.2009.07.004.

3. Reynard JM. Does anticholinergic medication have a role for men with lower urinary tract symptoms/ benign prostatic hyperplasia either alone or in combination with other agents?

Curr Opin Urol. 2004 Jan;14(1):13-6.

4. Wei JT, Calhoun E, Jacobsen SJ. Urologic diseases in America project: benign prostatic hyperplasia. DOI: 10.1097/01.ju.0000155709.37840.fe

5. McConnell JD, Roehrborn CG, Bautista OM, et al. Medical Therapy of Prostatic Symptoms (MTOPS) Research Group. The long-term effect of doxazosin, finasteride, and combination therapy on the clinical progression of benign prostatic hyperplasia. DOI: 10.1056/NEJMoa030656
6. Chacko KN, Donovan JL, Abrams P, et al. Peters TJ, Brookes ST, Thorpe AC, GujralS, Wright M, Kennedy LG, Neal DE. Transurethral prostatic resection or laser therapy for men with acute urinary retention: the Clas P randomized trial. J Urol. 2001 Jul; 166(1):166-70; discussion 170-1.

7. Madersbacher S, Marberger M. Is transurethral resection of the prostate still justified? BJU Int. 1999 Feb; 83(3):227-37.

8. Fraundorfer MR, Gilling P: holmium: YAG laser enucleation of the prostate combined with mechanical Morcellation: preliminary results. EUR Urol. 1998; 33 (1): 69-72.

9. Rassweiler J, Teber D, Kuntz R, Hofmann R. Complications of transurethral resection of the prostate (TURP)--incidence, management, and prevention. DOI:10.1016/j.eururo.2005.12.042

10. Hirasawa Y, Kato Y, Fujita K. Transurethral Enucleation with Bipolar for BenignProstaticHyperplasi a: 2-Year Outcomes and the Learning Curve of a Single Surgeon's Experience of 603 Consecutive Patients. doi: 10.1089/ end. 2017.0092. Epub 2017 May 25.

11. Hochreiter WW, Thalmann GN, Burkhard FC, Studer UE. Holmium laser enucleation of the prostate combined with electrocautery resection: the mushroom technique. J Urol 2002; 168(4):1470-1474.

12. Rassweiler J, Teber D, Kuntz R, Hofmann R. Complications of transurethral resection of the prostate (TURP)--incidence, management, and prevention. DOI:10.1016/j.eururo.2005.12.042

13. Oelke M, Bachmann A, Descazeaud A, et al. Emberton M, Gravas S, Michel MC, N'dow J, Nordling $\mathrm{J}$, de la Rosette JJ; European Association of Urology. EAU guidelines on the treatment and follow-up of nonneurogenic male lower urinary tract symptoms including benign prostatic obstruction. doi: 10.1016/j. eururo. 2013.03.004. Epub 2013 Mar 13.

14. Freyer PJ. Total enucleation of the prostate: a further series of 550 cases of the operation. Br Med J. 1919 Feb 1;1 (3031): 121-120.2.

15. Gilling PJ, Kennett KM, Fraundorfer MR. Holmium laser enucleation of the prostate for glands larger than $100 \mathrm{~g}$ : an endourologic alternative to open prostatectomy. J Endourol 2000; 14:529-531. 


\section{Original Research Article}

16. Ahyai SA, Gilling P, Kaplan SA, et al. Kuntz RM, Madersbacher S, Montorsi F, Speakman MJ, Stief CG. Meta-analysis of functional outcomes and complications following transurethral procedures for lower urinary tract symptoms resulting from benign prostatic enlargement. doi: 10.1016/j.eururo. 2010. 06.005. Epub 2010 Jun 11.

17. Neill MG, Gilling PJ, Kennett KM, et al. Randomized trial comparing holmium laser enucleation of prostate with plasmakinetic enucleation of prostate for treatment of benign prostatic hyperplasia. Urology 2006; 68(5):1020-1024.

17. Neill MG, Gilling PJ, Kennett KM, et al. Frampton CM, Westenberg AM, Fraundorfer MR, Wilson LC. Randomized trial comparing holmiumlaser enucleation of prostate with plasmakineticenucleation of prostate for treatment of benign prostatic hyperplasia. DOI: 10 . 1016/j. urology.2006.06.021

18. Liu C, Zheng S, Li $\mathrm{H}, \mathrm{Xu}$ k. Transurethral enucleation and resection of prostate in patients with benign prostatic hyperplasia by plasma kinetics. J Urol 2010; 184 (6): 2440-2445. doi: 10.1016/j. juro. 2010. 08.037 .

19. Fayad AS, Sheikh MG, Zakaria T, et al. Elfottoh HA, Alsergany R. Holmium laser enucleation versus bipolar resection of the prostate: a prospective randomized study. Which to choose?

doi: 10.1089/end.2011.0059. Epub 2011 Jul 11

20. Elshal AM, Elmansy HM, Elhilali MM. Feasibility of holmium laser enucleation of the prostate (HoLEP) for recurrent/residual benign prostatic hyperplasia (BPH). doi: 10.1111/j.1464-410X.2012.11290.x.Epub 2012 Jun 15.

21. Zhao Z, Zeng G, Zhong W, et al. Mai Z, Zeng S, Tao X. A prospective, randomised trial comparing plasmakinetic enucleation to standard transurethral resection of the prostate for symptomatic benign prostatic hyperplasia: three-year follow-up results. doi: 10.1016/j.eururo.2010.08.026. Epub 2010 Aug 20.

22. Seki N, Mochida O, Kinukawa N, et al. Sagiyama K, Naito S. Holmium laser enucleation for prostatic adenoma: analysis of learning curve over the course of 70 consecutive cases.

DOI:10.1097/01.ju.0000092035.16351.9d

23. Neill MG, Gilling PJ, Kennett KM, et al. Frampton CM, Westenberg AM, Fraundorfer MR, Wilson LC. Randomized trial comparing holmiumlaser enucleation of prostate with plasmakinetice nucleation of prostate for treatment of benign prostatic hyperplasia. DOI:10.1016/j.urology. 2006.06.021

24. Liu C, Zheng $\mathrm{S}$, Li $\mathrm{H}, \mathrm{Xu} \mathrm{K}$ : Transurethral enucleation and resection of prostate in patients with benign prostatic hyperplasia by plasma kinetics. J Urol. 2010; 184 (6): 2440-2445. doi: 10.1016/j.juro. 2010. 08.037 .

25. Liao N, Yu J. A study comparing plasmakinetic enucleation with bipolar plasmakinetic resection of the prostate for benign prostatic hyperplasia. DOI:10.1089/end.2011.0358

\section{How to cite this article?}

Reddy N. M, Reddy P.V., Reddy C.S., Reddy G. V, Ranadheer R, Bodduluri S, Maddiboina H. Safety and efficacy of Transurethral Bipolar Enucleation of prostate (TUBE) in BPH. Int J Med Res Rev 2018;6(05):243-251. doi:10.17511/ijmrr. 2018.i05.02. 